\title{
環軸椎後方固定術における合併症回避の工夫
}

\section{Complication Avoidance and Management in Posteriorly Instrumented C1-2 Fusion}

\author{
高見俊宏一八瀬努 石橋謙一 \\ 後藤剛夫露口尚弘大畑建 治
}

Toshihiro Takami, M. D., Tsutomu Ichinose, M. D., Kenichi Ishibashi, M. D.,

Takeo Goto, M. D., Naohiro Tsuyuguchi, M. D., Kenji Ohata, M. D.

\begin{abstract}
Objective : Once atlantoaxial joint instability has been detected, the goal of surgery is to reduce pathological subluxation, decompress neural elements and maintain vertebral column alignment. Herain, the surgical technique for internal fixation and fusion at the atlantoaxial joint is presented with an emphasis on complication avoidance.

Patients and methods : The patient record included a total of 12 patients with the atlantoaxial instability (11 male and 1 female), who underwent surgery over the past four years. The age of the patients ranged from 16 to 75 years old. Patients were classified into 7 in trauma group, and 5 in rheumatoid arthritis or degeneration group based on their etiology. Goel-Harms method with a cancellous screw and rod system was preferably used. In the cases of retroodontoid pseudotumor with chronic atlantoaxial instability, the posterior $\mathrm{C} 1$ arch was resected and combined with posterior fusion.

Results and conclusion: None of the patients demonstrated neurological deterioration after surgery. All of the patients with retroodontoid pseudotumor demonstrated neurological recovery with gradually diminishing pseudotumor. In one case treated by Megerl method, revision surgery was accomplished to achieve complete bone fusion. To avoid the surgical complications, selection and safe placement of $\mathrm{C} 2$ anchor screws, sufficient exposure of the lateral atlantoaxial joint, and fusion technique are key elements for successful surgery.
\end{abstract}

(Received : January 16, 2008 ; accepted : March 24, 2008)

\section{Key words}

atlantoaxial subluxation, lateral mass screw, pedicle screw, posterior fusion

\section{緒 言}

環軸椎後方固定術については，Gallie が 1939 年に Wiring 法による環軸椎後方椎弓間固定術を報告して以来 ${ }^{1)}$,

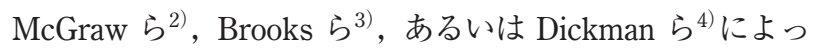
て改良術式が報告された。椎骨動脈を含めた血管損傷の リスクは少ないため，標準的術式として確立した。しか
し，単独で用いた場合には固定力は十分でなく，良好な 骨癒合を得るために術後に強固な外固定が必要である. この問題点を解決するために，近年では Magerl 法掞よ び Goel あるいは Harms 法に代表される強固な内固定を 用いた環軸椎後方固定術が主流となっている ${ }^{5-13)}$. C1 lateral mass screw および C2 pedicle あるいは pars interarticularis screw による環軸椎後方固定術は，Goel らがス

大阪市立大学大学院医学研究科脳神経外科 / T 545-8585 大阪市阿倍野区旭町 1-4-3〔連絡先：高見俊宏〕

Address reprint requests to : Toshihiro Takami, M. D., Department of Neurosurgery, Osaka City University Graduate School of Medicine, 1-4-3 Asahi-machi, Abeno-ku, Osaka- shi, Osaka 545-8585, Japan 
Table 1 Summary of 12 patients operated over the past 4 years : 2004-2007

\begin{tabular}{cccccc}
\hline $\begin{array}{c}\text { Patient } \\
\text { No. }\end{array}$ & Age & Sex & Chief complaint & Trauma & Diagnosis \\
\hline 1 & 49 & M & neck pain & + & C1-2 instability \\
2 & 63 & M & clumsy hand & - & retroodontoid pseudotumor \\
3 & 16 & M & neck pain & + & C1-2 instability \\
4 & 47 & M & gait disturbance & + & C1-2 instability \\
5 & 57 & M & dysesthesia & + & C1-2 instability \\
6 & 68 & M & clumsy hand & + & retroodontoid pseudotumor \\
7 & 62 & M & gait disturbance & - & retroodontoid pseudotumor \\
8 & 62 & M & gait disturbance & - & retroodontoid pseudotumor \\
9 & 25 & M & neck pain & + & C1-2 rotatory fixation \\
10 & 71 & F & clumsy hand & - & retroodontoid pseudotumor \\
11 & 67 & M & gait disturbance & + & retroodontoid pseudotumor \\
12 & 75 & M & gait disturbance & - & retroodontoid pseudotumor \\
\hline
\end{tabular}

クリュー+プレート内固定法を報告したのが最初で6), その後に Harms らが現在汎用されているスクリュー+ ロッド内固定法を報告した ${ }^{10)}$ 。最近 4 年間で経験した環 軸椎後方固定術 12 例について, 特に C1 lateral mass screw および C2 pedicle あるいは pars interarticularis screw による環軸椎後方固定術（本稿では Goel-Harms 法と呼称）における合併症回避の工夫について報告する.

\section{方法・症例}

\section{1 症例}

2004〜2007 年までの 4 年間で経験した環軸椎後方固定 術 12 例について検討した（Table 1)。症例の内訳は，男 性 11 例，女性 1 例で，年齢分布は 16 75 歳. 原因分類 では，外傷 7 例，リウマチ性あるいは変性 5 例であった。 12 例中 7 例において, 歯突起後方偽腫瘍を認めた。

\section{2 術前評価}

術前評価で最も注意した点は，1環軸椎亜脱臼の程度 および整復性，(2)軸椎椎弓根の太さ，および(3)椎骨動脈 の血行動態の 3 点である. (1)抒よび(2)については，骨変 形あるいは奇形が著しく CT 画像では判断困難な場合に は，実物大臓器立体モデルを作製した。(3)の椎骨動脈の 血行動態の評価では，MRA にて椎骨動脈の走行異常が 疑わしい場合は，3 次元造影 CT 画像での評価を行い立 体イメージとして理解した。ささらに，頭蓋内での対側あ るいは前方循環からの側副血行の程度についても確認し た。

\section{3 手術手技}

Goel-Harms 法における手術手技を記載する.

\section{1. 体位および術野展開}

腹臥位として行い，術中整復を試みる場合には，Crutch- field 型頭蓋牽引装置を装着し正中位で保持した。そのほ かは，Mayfield 型ヘッドピンを装着し，X 線透視装置で 整復位を確認しながら正中位で固定した。患者頭側には ナビゲーション装置あるいは X 線透視装置を配置した。外 後頭隆起と C7 棘突起の骨性隆起を目安として, 後頸部 正中に約 $5 \mathrm{~cm}$ の線状切開線をデザインした。項勒帯を 正中で切離して, 最初に軸椎棘突起に到達し，軸椎棘突 起に付着する大後頭直筋，下頭斜筋，多裂筋掞よび頸半 棘筋を骨膜下に剝離した。続いて，環椎後結節を確認し， 同部位に付着する小後頭直筋を骨膜下に剝離した．外側 への展開については，環椎では椎骨動脈の血管溝を確認 するまで，軸椎では第 2 頸神経根および $\mathrm{C} 2 / 3$ 椎間関節 の後面が確認できるまで行った.

\section{2. 軸椎スクリュー}

$\mathrm{C} 2 / 3$ 椎間関節内側縁および軸椎の椎弓根内側面を十分 に確認した. C2 pedicle screw では，C2/3 椎間関節内側 縁から外側上方に約 $5 \mathrm{~mm}$ の点に刺入点を設定した。内 側に 15〜25 度程度傾け，椎弓根内側に沿って刺入した。 C2 pars interarticularis screw では, C2 pedicle screw より も $2 \mathrm{~mm}$ 程度内側下方に刺入点を設定し，内側に 10 度 程度傾け，上下方向はあくまでも関節面に平行とした

(Fig. 1)。C2 pedicle あるいは pars interarticularis screw の刺入においては，内側方向のスクリューガイドには原 則としてナビゲーション装置を使用した。

\section{3. 外側環軸関節の露出と骨移植}

軸椎の椎弓根内側から上面の骨膜下剩離を椎体側に進 め，外側環軸関節に到達した。この操作で障壁となる第 2 頸神経とその周囲に発達する椎骨静脈叢については, Goel 原法に従い椎骨静脈叢を凝固しながら第 2 頸神経を 完全切断した (Fig. 2). 外側環軸関節を露出して, 骨移 植部位周辺の軟部組織を入念に摘除した。さらに，良好 
Fig. 1

Photographs showing the entry point and trajectory of a $\mathrm{C} 2$ pedicle screw (a) or a C2 pars interarticularis screw (b).
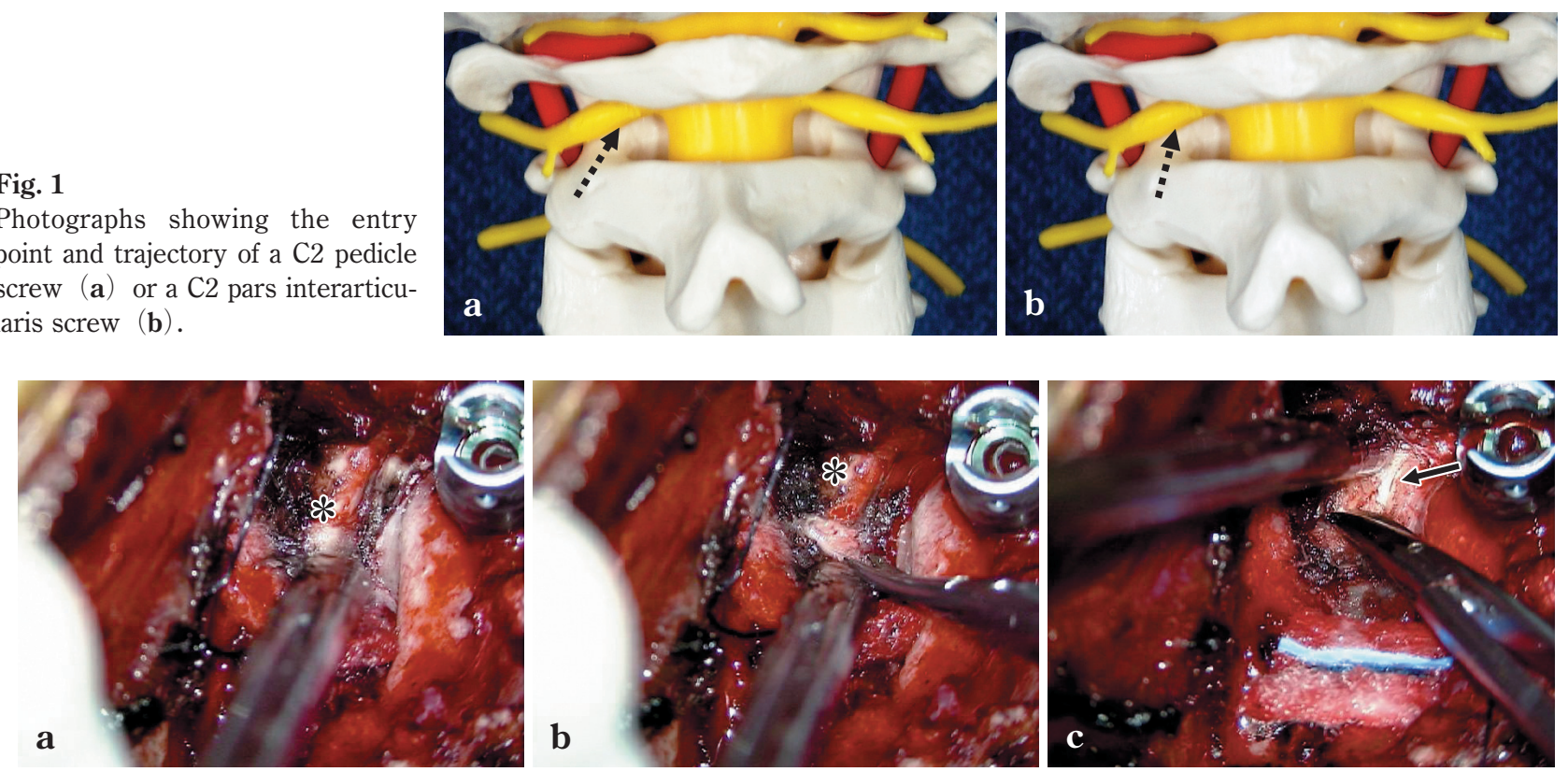

Fig. 2

Intraoperative photographs $\left(\mathbf{a}^{-} \mathbf{c}\right)$, corresponding to the boxed area in the spine model $(\mathbf{d})$, showing that the right $\mathrm{C} 2$ nerve $(*)$ was identified and sectioned at the $\mathrm{C} 2$ ganglion to expose the posterior surface of $\mathrm{C} 1-2$ lateral facet joint (arrow).

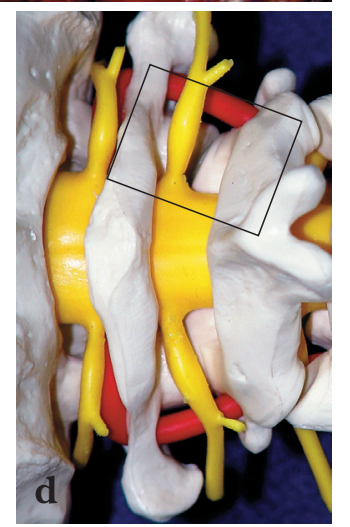

Fig. 3

Intraoperative photograph, corresponding to the boxed area in the spine model $(\mathbf{a})$, showing the entry point of C1 lateral mass screw (b).
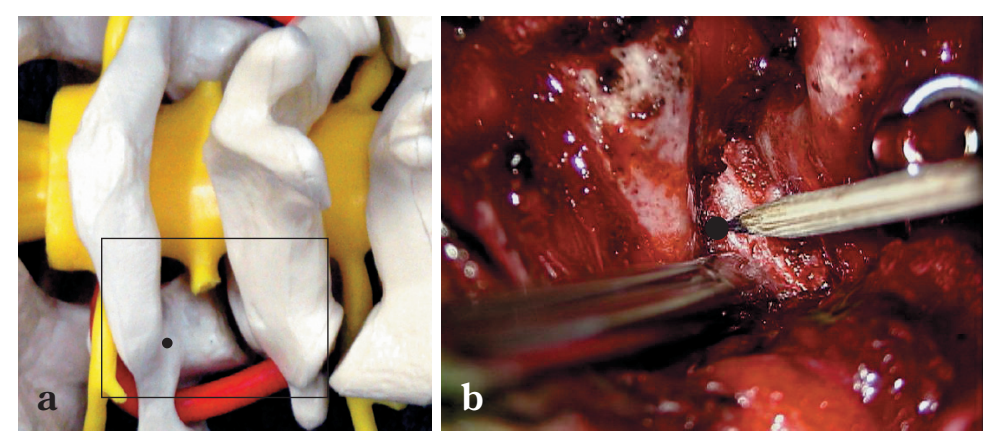

な骨癒合が得られるように，関節面から関節軟骨および 骨皮質を削除し，局所海綿骨（C2 あるいは C3 棘突起な どから採取）を移植した。

\section{4. 環椎椎弓切除および環椎スクリュー}

歯突起後方偽腫瘍の症例では環椎椎弓切除を行った.

C1 lateral mass screw の刺入にあたっては, Goel 原法に従 い椎弓下ルートとした。 外側塊内側面を確認し, その 3〜 $5 \mathrm{~mm}$ 外側に刺入ポイントを設定した（Fig. 3). X 線
透視をガイドとして, 環椎前弓に向かって内側に 15 度 程度傾けてスクリューを刺入した。

\section{5. 内固定の完成}

環椎および軸椎へのスクリュー刺入，亜脱臼整復およ び骨移植終了後に，最後にスクリュー連結を行った。ロッ ド長を調整して, 外側環軸関節に十分に圧迫をかけた状 態で環椎および軸椎スクリューを強固に連結した（Fig. 4)、整復位で固定するために, 最初に軸椎スクリューを 


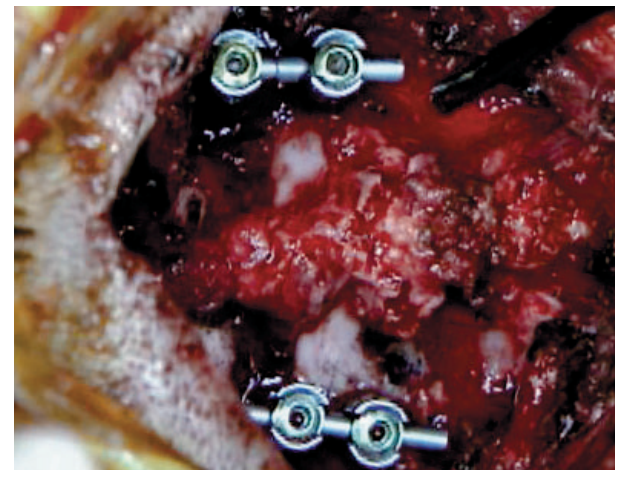

Fig. 4

Intraoperative photograph showing the placement of the cancellous screw and rod system in the atlantoaxial joint.

Table 2 Summary of surgical outcome : 2004-2007

\begin{tabular}{ll}
\hline Selection of surgical method & \\
$\mathrm{C} 1 / 2$ transarticular + Atlas claw & 4 patients \\
$\mathrm{C} 1$ lateral mass $-\mathrm{C} 2$ pedicle/pars & 5 patients \\
$\mathrm{C} 1$ lateral mass $-\mathrm{C} 2$ pedicle/translaminar & 2 patients \\
$\mathrm{C} 1$ lateral mass $-\mathrm{C} 3$ lateral mass & 1 patient \\
Screw malposition & none \\
Follow-up outcome & \\
postop neurological deficit & none \\
revision surgery for non-union & 1 patient $/ 12$ \\
retroodontoid pseudotumor & diminished in all \\
\hline
\end{tabular}

固定し，次に環椎スクリューを固定した。

\section{結 果}

\section{1 手術方法}

初期 4 例は Magerl 法を用いたが, 後半 8 例は GoelHarms 法を原則として用いた（Table 2). Goel-Harms 法を用いた 8 例中の 2 例においては, 椎骨動脈の軸椎レ ベルでの内側偏位が顕著であったために（いわゆる high riding vertebral artery), 軸椎 translaminar screw を代替法 として用いた ${ }^{14)}$ 。そのほか, リウマチ性骨破壊の顕著な 1 例では, 軸椎でのスクリュー刺入が困難と判断して C13 固定とした. 歯突起後方偽腫瘍の症例では, 偽腫瘍切 除は行わず環椎椎弓切除＋後方固定を行った ${ }^{13)}$.

\section{2 手術結果}

術後に新たな神経脱落症状を呈した症例はなく, 全例 において運動あるいは感覚障害の改善が観察された (Table 2). 現在までの術後フォローアップにおいては, 初 期に Magerl 法にて行った 1 例において, 十分な骨癒合

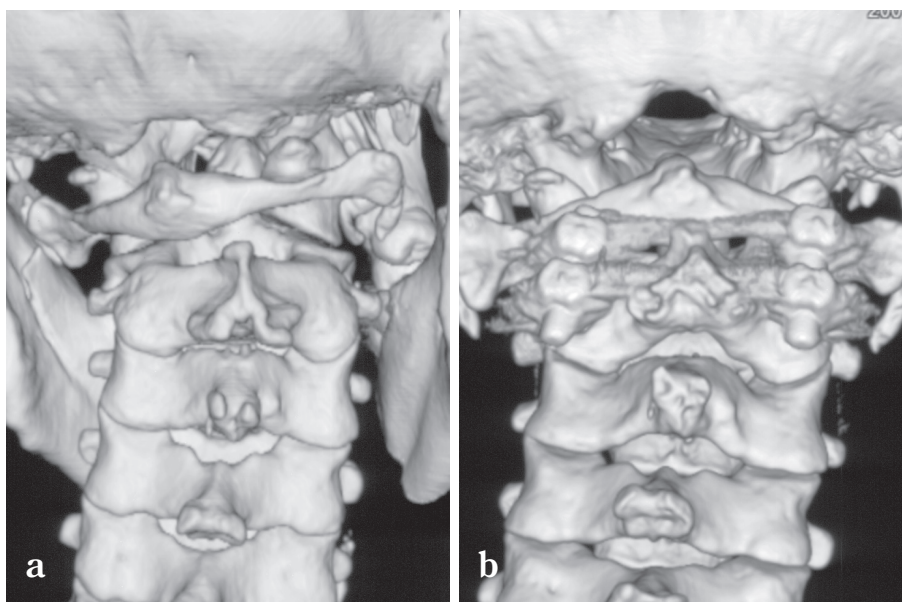

Fig. 5 Case 9

a : preoperative $3 \mathrm{D}-\mathrm{CT}$ showing the rotatory fixation of an atlantoaxial joint.

b : postoperative $3 \mathrm{D}-\mathrm{CT}$ showing the complete reduction of an atlantoaxial joint.

が得られず再建術を追加した。そのほかには，スクリュー 刺入あるいは固定に伴う合併症はなかった。歯突起偽腫 瘍の症例においては, 全例において術後早期から偽腫瘍 の縮小が観察できた。第 2 頸神経切断に伴い, 同支配域 に感覚障害が生じたが, 強い痛みなどの不快症状が遷延 した症例は経験しなかった。

\section{【代表症例：Case 9】}

\section{患 者：25 歳, 男性}

現病歴：2006 年 10 月にオートバイによる交通外傷を 受傷した。他院にて急性期の保存加療を受け，その後に ソフトネックカラーを装着していた. 受傷後 2 カ月頃か らネックカラーを外したが, 徐々に頸部の痛みが増強し, その後に頸部回旋制限が明らかとなった。当科初診時に は, 四肢症状はないものの, 外観上は斜頸位を呈してい た。頸部回旋を試みると, 強い痛みを自覚した。CT 画 像において環軸椎関節の亜脱臼状態を認め, 外傷後の回 旋型環軸椎亜脱臼症と診断した（Fig. 5 a). Goel-Harms 法による環軸椎後方固定術を行った. 術直後から頸部痛 は消失し，斜頸位は完全に正常位に回復した（Fig. 5 b). 術後 CT にてスクリュー刺入および外側環軸関節面に移植 した局所海綿骨に問題ないことを確認し (Fig. $6 \mathbf{a} \sim \mathbf{c})$, 術 6 力月後 CT にて良好な関節面の骨癒合を認めた（Fig. $6 \mathrm{~d} \sim \mathrm{f})$.

\section{【代表症例：Case 11】}

患 者：67 歳, 男性

現病歴：約 20 年前と 10 年前に 2 回の交通外傷の既往 があり, 2 回目の事故後から頸部痛が顕著となり頸部回 旋が困難となった。数年前から頸部不随意運動が出現す 

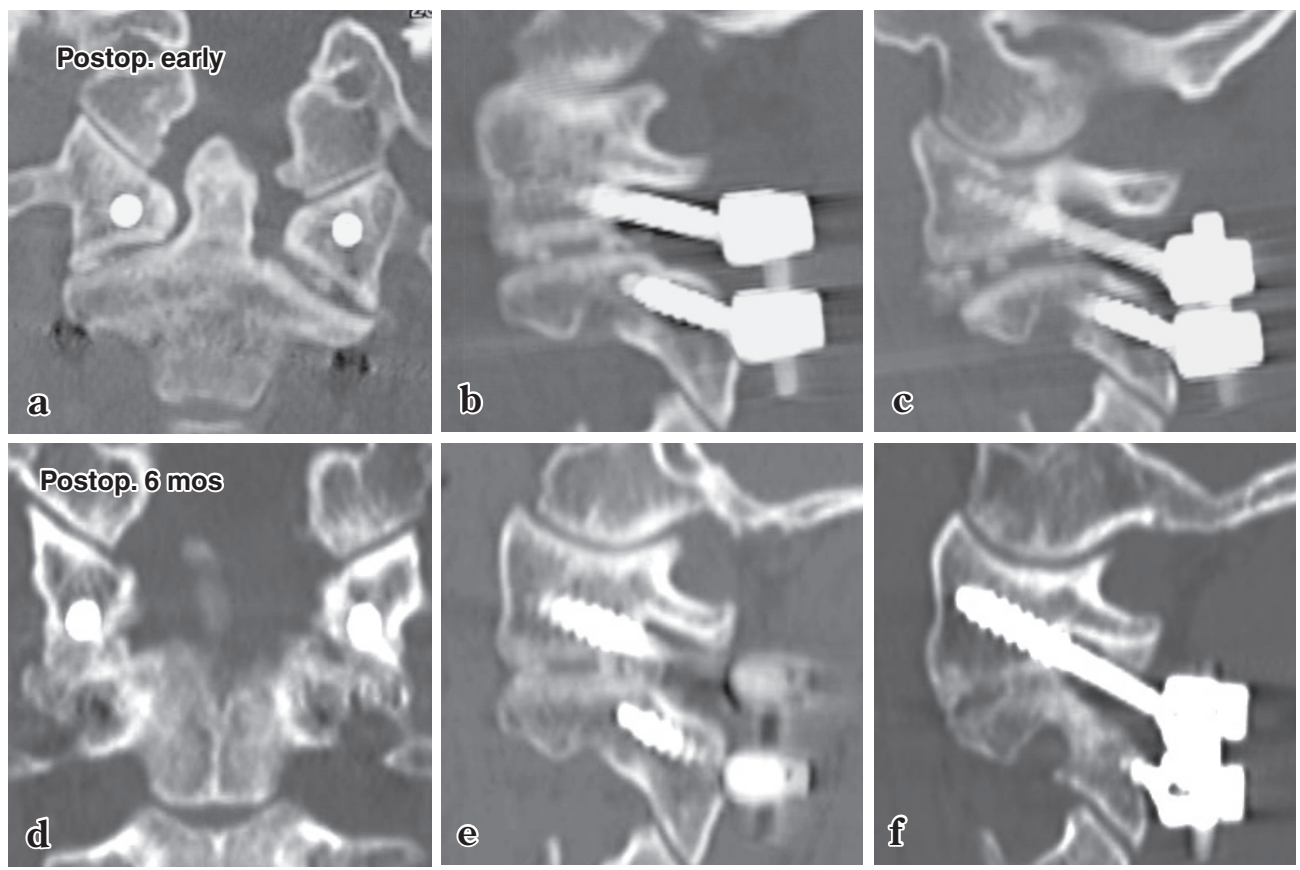

Fig. 6 Case 9

$\mathbf{a}^{-} \mathbf{c}$ : postoperative CT, obtained early after surgery, showing the adequate placement of screws and autologous bone grafting into the lateral atlantoaxial joints.

d-f : postoperative CT, obtained 6 months after surgery, showing satisfactory bone fusion at the lateral atlantoaxial joints.

るようになり，外観上は斜頸位を呈するようになった。 さらに, 四肢の違和感が明瞭となり, 最近では平地歩行 にも支障をきたすようになった．神経学的には高度脊髄 症を呈していた.CT 画像において環軸椎の回旋型亜脱 臼状態を認め, MRIにて歯突起後方に偽腫瘍があり春䯣 高度圧迫を認めた（Fig. 7 a). 慢性環軸椎亜脱臼症㧍よ び歯突起後方偽腫瘍と診断し, 後方から環椎椎弓切除求 よび Goel-Harms 法による環軸椎後方固定術を行った。

一側の軸椎 pedicle screw の刺入が困難と思われたため, 軸椎 translaminar screw を代替法として用いた（Fig. 7 b). 術直後から頸部痛は消失し, 完全ではないものの斜 頸位の改善が得られた。脊髄症も徐々に改善し, 術後 3 力月の時点に扔いて平地歩行にはまったく支障がない程 度にまで改善した。術後の経時的 MRI では, 術後早期か ら歯突起後方偽腫瘍の消退があり, 脊髄描出が良好となっ た (Fig. 7 c).

\section{考 察}

環軸椎後方固定術においては, 術後外固定の軽減を目 指して, 近年では強固な内固定を行う術式が主流となっ てきた ${ }^{5-13)}$ 。外側環軸関節をスクリューで貫通させる
Magerl 法は，後方椎弓間固定術を併用すれば外側 2 点と 後方の強固な内固定が得られる ${ }^{11)}$. しかし, 亜脱臼整復 が困難な症例, あるいは頸胸椎の後弯変形が高度な場合 には適応が難しい.また, 椎骨動脈の軸椎レベルでの内 側偏位が高度な症例（いわゆる high-riding vertebral artery）では，手技的に椎骨動脈損傷のリスクが高いこ とが懸念される. Magerl 法における椎骨動脈損傷リスク については, Wright ら ${ }^{15)}$ が患者 1 人あたり $4.1 \%$ ，スク リュー 1 本あたり $2.2 \%$ と報告しており，決して軽視で きない率と思われる. さらに, 環椎椎弓切除が必要な症 例では, 後方椎弓間固定術を行うことができないために 骨移植が問題となる.

一方，環椎および軸椎の個々にスクリューを刺入して 連結固定する Goel-Harms 法は, 1994 年に Goel らが久 クリューとプレートで内固定する術式を報告したのが最 初で6)，次いで 2001 年に Harms らが現在汎用されてい るスクリューとロッドで内固定する術式を報告した ${ }^{10)}$. 環椎と軸椎スクリューが独立しているため, 術中整復と 固定が可能であること, 頸胸椎の後弯変形に影響を受け ないことを利点として挙げることができる. 椎骨動脈損 傷リスクについては, Magerl 法と比較して手技的なリス ク軽減が期待できる。ささらに, 外側環軸関節に骨移植を 

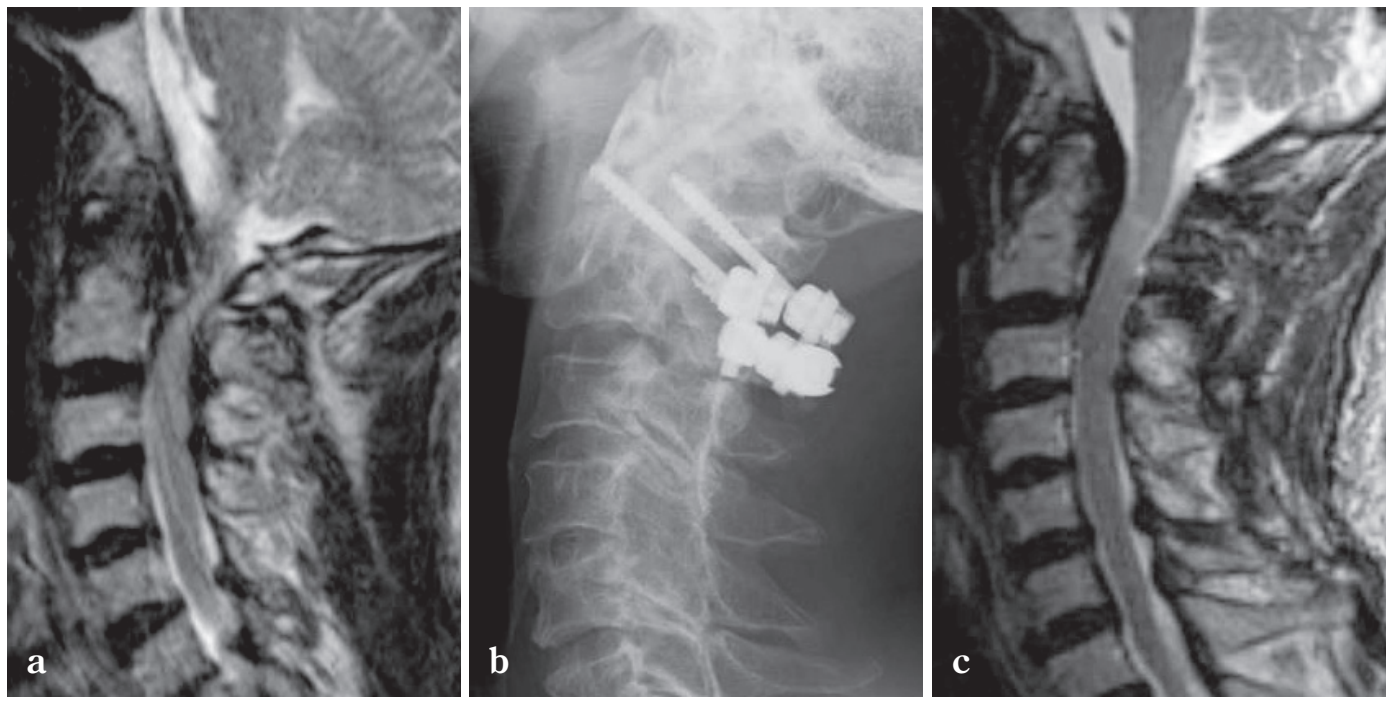

Fig. 7 Case 11

a : preoperative T2-weighted MR image showing severe compression of the spinal cord caused by a retro-odontoid pseudotumor.

b : postoperative lateral radiograph of the cervical spine showing the internal fixation of the atlantoaxial joint using the alternative method of translaminar screw.

c : postoperative T2-weighted MR image, obtained 3 months after surgery, showing sufficient decompression of the spinal cord and the diminished retro-odontoid pseudotumor.

行うため，環椎椎弓切除を行う場合にも骨移植が問題と なることはない. Goel-Harms 法の生体力学的な固定力 については, Magerl 法と比べて遜色ない固定結果が報告 されている16,17).

Goel-Harms 法の問題点としては，(1)必ずしも C2 pedicle あるいは pars interarticularis screw の安全な刺入が可 能とは限らないこと, (2)外側環軸関節の露出に際して第 2 頸神経周囲の椎骨静脈叢からの静脈性出血に難渋する 点が挙げられる. (1)内固定のための軸椎スクリューの選 択㧍よび刺入に扔いては，C2 pedicle あるいは pars interarticularis screw に固執せず，術前検討で安全な刺入が可 能と判断した場合のみ選択し, そのほかの場合には translaminar screw などの代替法を選択することが可能であ $3^{14)} .3$ 次元 CT 画像を詳細に読影することは必須であっ たが，骨変形あるいは奇形が著しい場合には決して容易 ではなく，そのような場合には CT 画像から作製した実 物大臟器立体モデルが有用であった。椎骨動脈の評価に ついては, 術前に椎骨動脈の走行, 偏位および左右優位 性などを検討しておくことは必須であったが, 頭蓋内で の側副血行動態についても理解しておくことが重要と思 われた. (2)外側環軸関節の露出に関しては, 環椎後方要 素を残す場合には, 環軸椎後方椎弓間固定による代替法 が簡便で有用である ${ }^{1-4)}$. 環軸椎後方椎弓間固定を追加 する場合のデメリットは，別個に腸骨などから移植骨を
塊として（海綿骨ではなく）採取する必要があることが 挙げられる. 第 2 頸神経を切断して外側環軸関節に骨移 植する本術式では, 外側環軸関節の間隙面が極めて小さ いため, C2 あるいは C 3 棘突起などからのわずかな局所 海綿骨で十分なことがメリットである。第 2 頸神経周囲 の椎骨静脈叢からの静脈性出血については, Goel 原法に 従い椎骨静脈叢を凝固しながら第 2 頸神経を脊髄神経節 部分で切断することが最も確実であった. 上体挙上など による静脈梐血の緩和，あるいはフィブリン糊およびコ ラーゲンスポンジによる局所止血も有効ではあるが, 外 側環軸関節を直視下に十分に露出するには不十分と思わ れた. 椎骨静脈叢は網目ネットワーク構造のため, 部分 的に凝固切断しても静脈性血行障害は生じることはなく, 実際, 本報告例においても術後に静脈血行障害による症 状発現は経験しなかった。また，第 2 頸神経切断につい ても, 強い痛みなどの不快症状が遷延した症例は経験せ ず, 外側環軸関節の十分な露出においては, 椎骨静脈叢 を凝固しながら第 2 頸神経を脊髄神経節部分で切断する ことは有用な手術ステップと思われる.さらに, 外側環 軸関節への骨移植については, 金属内固定が骨癒合完成 までの仮支えであることから，本術式における最重要の 手術ステップと思われる. 


\section{結＼cjkstart語}

Goel-Harms 法による環軸椎後方固定術における合併症 回避の工夫について報告した。手術に際して特に注意し た点は，(1)内固定のための軸椎スクリューの選択および 刺入，(2)外側環軸関節の十分な露出，(3)骨移植であった。 金属内固定はあくまでも骨癒合完成までの仮支えである ため，その刺入法よりも骨移植に重点を置いた手術を計 画するべきであり，その前提として局所解剖の理解と術 前評価が重要と思われる。

\section{文 献}

1) Gallie WE : Fractures and dislocations of the cervical spine. Am J Surgery $\quad 46: 495-499,1939$

2) McGraw RW, Rusch RM : Atlanto-axial arthrodesis. J Bone Joint Surg Br 55 : 482-489, 1973

3) Brooks AL, Jenkins EB : Atlanto-axial arthrodesis by the wedge compression method. J Bone Joint Surg Am $60: 279-284,1978$

4) Dickman CA, Sonntag VK, Papadopoulos SM, et al : The interspinous method of posterior atlantoaxial arthrodesis. J Neurosurg 74:190-198, 1991

5) Dickman CA, Sonntag VK : Posterior C1-C2 transarticular screw fixation for atlantoaxial arthrodesis. Neurosurgery $\quad 43: 275-281,1998$

6) Goel A, Laheri V : Plate and screw fixation for atlantoaxial subluxation. Acta Neurochir (Wien) 129:47-53, 1994

7) Goel A, Desai KI, Muzumdar DP : Atlantoaxial fixation using plate and screw method: a report of 160 treated patients. Neurosurgery $\mathbf{5 1}:$ 1351-1357, 2002

8) Goel A, Kulkarni AG, Sharma P : Reduction of fixed atlantoaxial dislocation in 24 cases : technical note. $J$ Neurosurg Spine 2: 505-509, 2005

9) Haid RW Jr : C1-C2 transarticular screw fixation : technical aspects. Neurosurgery $49: 71-74,2001$

10) Harms J, Melcher RP : Posterior C1-C2 fusion with polyaxial screw and rod fixation. Spine 26:2467-2471, 2001

11) Magerl F, Seemann PS : Stable posterior fusion of the atlas and axis by transarticular screw fixation, in Kehr P, Weidner A (eds) : Cervical Spine. Berlin, Springer-Verlag, 1986, pp322-327

12) Neo M, Sakamoto T, Fujibayashi $S$, et al : A safe screw trajectory for atlantoaxial transarticular fixation achieved using an aiming device. Spine 30 : E236-242, 2005

13) Takami T, Goto T, Tsuyuguchi N, et al : Posterior $\mathrm{C} 1-2$ fixation with cancellous screw and rod system for retroodontoid pseudotumor associated with chronic atlantoaxial subluxation. Technical note. Neurol Med Chir (Tokyo) 47: 189-194, 2007

14) Wright NM : Translaminar rigid screw fixation of the axis. Technical note. J Neurosurg Spine 3:409-414, 2005

15) Wright NM, Lauryssen $\mathrm{C}$ : Vertebral artery injury in $\mathrm{C} 1$ 2 transarticular screw fixation : results of a survey of the AANS/CNS section on disorders of the spine and peripheral nerves. American Association of Neurological Surgeons/Congress of Neurological Surgeons. J Neurosurg 88:634-640, 1998

16) Hott JS, Lynch JJ, Chamberlain RH, et al : Biomechanical comparison of $\mathrm{C} 1-2$ posterior fixation techniques. $J$ Neurosurg Spine 2:175-181, 2005

17) Melcher RP, Puttlitz CM, Kleinstueck FS, Lotz JC, Harms J, Bradford DS : Biomechanical testing of posterior atlantoaxial fixation techniques. Spine 27:24352440, 2002 